\title{
TURNPIKE STABILITY OF DECOMPOSABLE SYSTEMS AND THE EFFICIENCY OF GROWTH PLANNING*
}

\author{
TOYOAKI WASHIDA
}

In this paper, the optimal capital accumulation paths of decomposable dynamic input-output models are examined. This problem is not only important but contemporary, because in solving a worldwide urgent problem of finding better industrial and trade structures, we must pay attention to the decomposability of national economy and must have an insight into a sub-economy which has higher capability of growth. Nevertheless, these aspects of models so far have been neglected, because of complexity of theoretical treatments.

Here, two problems are obserbed. First, how does each sub-economy, which is closely related, behaves on optimal paths ? Second, does the capital accumulation planning in decomposable systems retain their efficiency as well as in indecomposable systems? Within the limitation of our discussions to the cases that the independent sub-economy has a higher Neumann growth factor than the dependent, we can answer these questions as follows. First, we can show that the dependent sub-economy converges to the turnpike in long term planning, while the independent sub-economy does not necessarily do so. Second, the planning is possibly inefficient if the initial stocks of the independent sub-economy are excess for supporting optimal growth of the dependent sub-economy. Furthermore, the numerical examples are provided for the case of Japanese economy.

\section{Decomposability of Economies and Turnpike Theories}

The turnpike theories provide important information about the characteristics of the growth paths and the capability of economic growth when we plan optimal growth of economies. The theories show that the optimal paths converge to the balanced growth paths with the maximal growth rate, that is called "turnpike", during the most of planning periods. Especially, in capital acumulation programs, these characteristics are independent of objective functions. Because of the simplicity to make national consensus among people with various attitudes toward final states, the turnpike properties have been attracting our attentions. The consensus to be attained will

*) This paper was read at the 8 th International Conference on Input-Output Techniques, Sapporo, Japan, July 1986.

The author is greatly indebted to Prof. Jinkich Tsukui (Institute of Social and Economic Research in Osaka University) for many suggestions and encouragements. 
merely be to go along the turnpike. Therefore, planning authorities are enough in paying attention so as to make economies move to the turnpike. This method, however, is applicable only to the cases of indecomposable economies, which have no such sub-economy as been able to sustain its own growth without any supports from the other economies. In this case, we can easily find that the turnpike, on which all industries can grow with a uniform rate, would be exist uniquely.

In contrast to the high usefulness of turnpike theories, the characteristics of a uniform growth rate may be put up some questions from the view point of economic reality. Actually the observed differences in growth rates among industrial groups give some insights to the decomposability of economic systems. In fact, this decopossbility of economies of industrialized countries is pointed out by Simpson and Tsukui (1965). They show that the metallic industries have rather strong decomposability. In such decomposable economies, we cannot apply above discussions, because the turnpike is not necessarily unique, and possibly multiple turnpikes exist or all products are not produced on the turnpike. It is clear that the products which are not produced on optimal paths and not valued by the final objective function must be discarded on the way of optimal paths. And the main problem is that products not produced on the turnpike are valued by the objective function. In this paper, we would mainly concern with these situations.

We should pay attention to another aspect of the decomposable systems. The relations between industrial structure and international trade are closely connected with decomposability of economies. For example, if almost, but not strictly, independent sub-economy cannot attain a rapid growth owing to the inferiority of the tech. niques of the other sub-economies, we can import these products in exchange of the export of former sub-economy. It is sure that there are some risks to execute this industrial policy. Because it will compel the dependent sub-economies to make weaker than before and to deprive the independency from the nation. It may also generate frictional unemployments because of the movement of laborers over industries. We shall call these changes of industrial structure as "the technological special. ization in international trades".

The greater part of the studies of turnpike theories have so far been excluding the cases of decomposable economies. It is mainly due to the concentration of concerns on the theoretical studies, because the indecomposability ensures a important 
tractability. The troubles which decomposability brings in the theoretical treatment of a optimal growth problem have two aspects. First, as above described, some of turnpikes do not have a strictly positive output configuration. Second, even if one of output configurations as turnpike has strictly positive one, the set of prices which ensure the normal profit to the activities employed on this turnpike is not strictly positive one. In these cases Mckenzie (1967) shows that the optimal paths converge to the Neumann facet during certain portion of planning periods. But he does not show that the optimal paths converge to the turnpike, We should pay attention to the fact that the facet is an incomplete one when Neumann price vector is not strictly positive.

We should refer to the studies on the duality of von Neumann model, discussions of which began by Morishima (1971). It has been developed to decide all wage-profit frontiers related to the decomposability of the model. But these studies do not mention to the turnpike properties of optimal capital accumulation paths of von Neumann type of model ${ }^{1}$.

Tsukui and Móczár (1984) investigate the optimal growth paths of decomposable economies quite carefully. First, they give the characteristics of von Neumann solutions which especially depend on each growth rate of sub-economies. And some numerical examples are given in Japanese economies. The notable results are that in most cases the dependent economy has strong tendencies to converge to its own turnpike. We should say that they are obtained by the device to calculate each proportions of output of sub-economies independently. In the following part, we investigate the turnpike properties with a theoretical point of view on the bases of these studies. Consequently, we will carry this studies to the planning efficiency of decomposable economies.

\section{Turnpike stability of dependent economies}

We adopt a closed dynamic input-output model. For simplicity, we premise that each industry has only one set of techniques. $A=\left(a_{1 j}\right)$ is the augmented input coefficient matrix, which also involves final demand, such as consumption, government expenditure, and net export, except for investment. $a_{1 j}{ }^{\prime}$ s express the amount of ith

1) the papers related to this subject are Morishima (1976), and Bromek (1974). The important discussions about turnpike theorem of von Neumann model are in Morishima (1970), Mckenzie (1968) and Tsukui (1967). 
product $(i=1,2, \ldots, n)$ which is necessary to produce one unit of jth products. $B=$ $\left(b_{i j}\right)$ is a capital coefficient matrix and $b_{i j}$ 's express the amount of capital stocks made up of ith product which is necessary to produce one unit of jth product. Therefore the technology of $j$ th industry $(j=1,2, \ldots, n)$ can be expressed with column $\left(a_{1 j}, a_{2 j}, \ldots\right.$ ,$\left.a_{n j}\right)$ in matrix $A$ and a column $\left(b_{1 j}, b_{2 j}, \ldots, b_{n j}\right)$ in matrix $B$.

Now we suppose that this economy is decomposable. Matrixes are represented as follows.

$$
A=\left(\begin{array}{cc}
A_{11} & A_{12} \\
0 & A_{22}
\end{array}\right) \quad B=\left(\begin{array}{cc}
B_{11} & B_{12} \\
0 & B_{22}
\end{array}\right)
$$

where $A_{i j}, B_{1 j}$ are the sub-matrixes of $A, B$ respectively and both $A_{11}$ and $B_{11}$ are $m \times$ $m$ matrix $(m<n)$. We refer to the economy, which involves industries numbered from 1 to $\mathrm{m}$, as 1 st-economy and the other as $2 \mathrm{nd}$-economy. We can see that the system has a hierarchical input structure, that is the 1st-economy can grow without any products of 2nd-economy, on the other hand, products of 1st-economy are essential for 2nd-economy as far as $\mathrm{A}_{12}$ or $\mathrm{B}_{12}$ contain at least one positive element.

Now we investigate Leontief trajectories ; for all products, supply and demand are in an equilibrium, and capital stocks are completely utilized in every periods. let $\mathrm{x}(\mathrm{t})$ be a column vector of output in period $t$. Then trajectories are expressed by the following equation.

$$
\mathrm{x}(\mathrm{t})=\mathrm{Ax}(\mathrm{t})+[\mathrm{Bx}(\mathrm{t}+1)-\mathrm{Bx}(\mathrm{t})],
$$

where the left hand side represents the supply of products in period $t$, the first term of the right hand side represents the intermediate demand for production, and the second term is the investment demand. Owing to the above assumption, the capital stocks of the next period equal to $\mathrm{Bx}(\mathrm{t}+1)$. The levels of production in period $\mathrm{t}+1$ are decided under the restriction to attain the complete utilization of the capital stock augmented by investments in period t. Consequently, the paths given by (1) are the same as Harrod's warranted growth paths. Next, we construct the balanced growth paths which fulfill (1). Before that, let the balanced growth rates and configurations, related to each subeconomy, be $g_{1}, \hat{x}_{1}(i=1,2)$ respectively. They should satisfy following equations.

$$
\begin{aligned}
& \left(I_{1}-A_{11}\right) \hat{x}_{1}=g_{1} B_{11} \hat{x}_{1} \\
& \left(I_{2}-A_{22}\right) \hat{x}_{2}=g_{2} B_{22} \hat{x}_{2},
\end{aligned}
$$


where $I_{1}(i=1,2)$ are unit matrixes of the corresponding dimension. Then the balanced growth solution of (1), $\mathrm{g}$ and $\mathrm{x}$, must satisfy the equation,

$$
(\mathrm{I}-\mathrm{A}) \mathrm{x}=\mathrm{gBx} \text {, }
$$

where $I$ is unit matrix. We devide the vector $\mathrm{x}$ into $\mathrm{x}_{1}$ and $\mathrm{x}_{2}$ corresponding each subeconomies. Then (2) is written as follows.

$$
\begin{aligned}
& \left(\mathrm{I}_{1}-\mathrm{A}_{11}\right) \mathrm{x}_{1}=\mathrm{gB}_{11} \mathrm{x}_{1}+\mathrm{gB}_{12} \mathrm{x}_{2}+\mathrm{A}_{12} \mathrm{x}_{2} \\
& \left(\mathrm{I}_{2}-\mathrm{A}_{22}\right) \mathrm{x}_{2}=\mathrm{gB}_{22} \mathrm{x}_{2}
\end{aligned}
$$

We assume $g_{i}>0, \hat{x}_{1}>0(i=1,2)$. If $g_{1} \leqq g_{2}$ is held, then as far as at least one element of $A_{12}$ or $B_{12}$ is positive, there is no solution except for $g=g_{1}, x=\left(\hat{x}_{1}, 0\right)^{\prime}$, which satisfy the above equations. In other words, the fact that the growth rate of the 2 nd -economy is higher than 1st-economy represents that the technology of the 2ndeconomy is superior to that of the 1st-economy, therefore the 1st-economy cannot support the rapid growth of the 2nd-economy through the supply of products. But if $\mathrm{g}_{1}>\mathrm{g}_{2}$, there appears multiple solutions, that is, both $\mathrm{g}=\mathrm{g}_{1}, \mathrm{x}=\left(\hat{\mathrm{x}}_{1}, 0\right)^{\prime}$ and $\mathrm{g}=\mathrm{g}_{2}, \mathrm{x}=$ $\left(\tilde{\mathrm{x}}_{1}, \widehat{\mathrm{x}}_{2}\right)$ 'satisfy above equations, where $\tilde{\mathrm{x}}_{1}$ are defined as follows.

$$
\tilde{\mathbf{x}}=\left(\mathrm{I}_{1}-\mathrm{A}_{11}+\mathrm{g}_{2} \mathrm{~B}_{11}\right)^{-1}\left(\mathrm{~g}_{2} \mathrm{~B}_{12}+\mathrm{A}_{12}\right) \hat{\mathrm{x}}_{2} \text {. }
$$

Whether this vector is positive or not is one of important question. But it is easily seen that under assumptions given later it is ensured to be positive.

Now we construct a optimal capital accumulation problem. Let the length of the term of planning be $T$. The object is to maximize the final level of capital stocks with certain given proportion of respective capital stocks. Although the other objects can be given, for example that of maximizing total value of final stocks, we do not adopt them in this paper, because they can not bring the good perspective to discuss our subjects. This planning problem can be specified as follows.

$\max . \mathrm{q}$

s.t.

$$
\begin{aligned}
& (I-A+B) x(t)-B x(t+1) \geqq 0 \quad t=0,1,2, \ldots, T-1 \\
& (I-A+B) x(T)-\mathrm{qv}_{2}{ }^{T} s \geqq 0 \\
& x(t) \geqq 0 \quad t=0,1,2, \ldots, T
\end{aligned}
$$

where $(\mathrm{I}-\mathrm{A}+\mathrm{B}) \mathrm{x}(0)$ is initially given so as to be strictly positive vector and $\mathrm{v}_{2}$ is a scalar given later. It is clear that the existence of this scalar cannot influence to the optimal paths. We should pay attention to the fact that this planning problem does not imply the decomposability of economy.

Here we give the basic assumptions. 
Assumption 1: $\quad I_{i}-A_{11} i=1,2$ satisfy the Hawkins-Simon condition and $A_{11} i=1,2$ are indecomposable.

Assumption 2: $\mathrm{B}_{11} \mathrm{i}=1,2$ are nonsingular matrixes.

Assumption 3: $\mathrm{A}_{12}, \mathrm{~B}_{12} \geqq 0$ and $\neq 0$.

Assumption 4: $s=\left(s_{1}, s_{2}\right)^{\prime}$ and $s_{1} \geqq 0, s_{2} \geqq 0$. And at least one element of $s_{2}$ is positive.

Assumption 5: $1 / \mathrm{g}_{1} \mathrm{i}=1,2$ are the Frobenius eigenvalue of $\left(\mathrm{I}_{1}-\mathrm{A}_{11}\right)^{-1} \mathrm{~B}_{11}$ respectively. Let $\mathrm{v}_{1}=1+\mathrm{g}_{\mathrm{i}}$. Furthermore the absolute values of the other eigenvalues of $I_{1}+\left(I_{1}-A_{11}\right) B_{11}^{-1}$ are different from $v_{1}$.

Since our B matrix involves inventory investment, assumption 2 may not lose a economic reality. The above assumptions are fundamental but insufficient to proceed our discussions. We must add the following assumption.

Assumption 6: $\mathrm{g}_{1}>\mathrm{g}_{2}$.

This is, however, rather strong assumption, because it limits the scope of our discussions. It depends on the fact that our studies belong to the first stage of the analysis of decomposable economy.

Under these assumptions, we can prove the turnpike stability of optimal paths of 2nd-economy. Since we already show the characteristics of Neumann output configuration. We discuss the dual solution of them. Let $\hat{\mathrm{p}}_{1}, \hat{\mathrm{p}}_{2}$ be the Neumann price vector of each economies, that is, the following equations are satisfied.

$$
\begin{aligned}
& \hat{\mathrm{p}}_{1}\left(\mathrm{I}_{1}-\mathrm{A}_{11}\right)=\mathrm{g}_{1} \hat{\mathrm{p}}_{1} \mathrm{~B}_{11} \\
& \hat{\mathrm{p}}_{2}\left(\mathrm{I}_{2}-\mathrm{A}_{22}\right)=\mathrm{g}_{2} \hat{\mathrm{p}}_{2} \mathrm{~B}_{22}
\end{aligned}
$$

We see that the assumption 1,2 ensure $\left(I_{1}-A_{11}\right)^{-1} B_{11}>0 i=1,2$. Consequently, all of Neumann prices and output configurations are strictly positive, that is $\hat{\mathrm{p}}_{1}>0, \hat{\mathrm{x}}_{1}>0$ $(i=1,2)$. Now we can give the Neumann price solution of the total economy under the interest rate $g_{2}$. Neumann price vector is $p=\left(0, \hat{p}_{2}\right)$, to which corresponding Neumann output configuration is $\mathrm{x}=\left(\tilde{\mathrm{x}}_{1}, \tilde{\mathrm{x}}_{2}\right)^{\prime}$.

Now let the maximum of $r$, which satisfy $r B x \leqq(I-A+B) x(0)$, be $r^{*}$. According to $(\mathrm{I}-\mathrm{A}+\mathrm{B}) \mathrm{x}(0)>0$ and Assumption 2, $\mathrm{r}^{*}$ is positive. Since we have never been setting the scale of vector $\mathrm{x}=\left(\tilde{\mathrm{x}}_{1}, \tilde{\mathrm{x}}_{2}\right)^{\prime}$, we can regard the vector $\mathrm{x}$ as $\mathrm{r}^{*} \mathrm{x}$. Thus we have $(I-A+B) x-v_{2} B x=0$. This means that the paths,

$$
\mathrm{x}(0), \mathrm{x}, \mathrm{v}_{2} \mathrm{x}, \mathrm{v}_{2}{ }^{2}, \ldots, \mathrm{v}_{2}{ }^{\mathrm{T}-1}
$$

are one of feasible path which satisfies conditions of problem A. This paths play 
crucial rolls to prove the turnpike stability as the comparative paths of optimal paths. It is a routine method which have been developed and used by many authors. Then let the attainable maximum $q$ by this feasible path in the problem $A$ be $\hat{q}$. Thus we have $\hat{\mathrm{q}} \geqq \mathrm{q}^{*}$, where $\mathrm{q}^{*}$ is the optimal solution, because every feasible solution can not be larger than optimal solution. At the same time, we have the following inequalities.

$$
\begin{aligned}
& (\mathrm{I}-\mathrm{A}+\mathrm{B}) \mathrm{x}(\mathrm{T}) \geqq \mathrm{v}_{2}^{\mathrm{T}} \mathrm{q}^{*} \mathrm{~s} \\
& (\mathrm{I}-\mathrm{A}+\mathrm{B}) \mathrm{v}_{2}{ }^{\mathrm{T}-1} \mathrm{x} \geqq \mathrm{v}_{2}^{\mathrm{T}} \text { वิs. }
\end{aligned}
$$

Here we have $\hat{\mathrm{q}}>0$. Because $\mathrm{Bx}>0$ is given owing to assumption 2, and the left-hand side of above equation is strictly positive vector, on account of $(I-A+B) x=v_{2} B x$. Furthermore we must pay attention to the fact that if both sides of (6) are divided by $\mathrm{V}_{2}^{\mathrm{T}}, \mathrm{T}$ disappear completely, thus $\hat{\mathrm{q}}$ is determined regardless of the planning term $\mathrm{T}$.

In this stage, if we adopt the assumption of indecomposability, we can easily prove the convergence to the path on which every products is utilized in each periods, that is one of Leontief trajectories. This is decisively depend upon the fact that the Neumann price vector is strictly positive in indecomposable systems. Therefore, the value loss of the divergence from the Leontief trajectory can be estimated by that prices. Our system, however, do not employ this assumption. Nevertheless, we can show that the optimal paths of the 2nd-economy converge to one of the leontief trajectories. To see this, we define the residual vectors $r(t)(t=0,1,2, \ldots, T-1)$ of the optimal path, that is,

$$
(\mathrm{I}-\mathrm{A}+\mathrm{B}) \mathrm{x}(\mathrm{t})-\mathrm{Bx}(\mathrm{t}+1)=\mathrm{v}_{2}^{\mathrm{T}} \mathrm{r}(\mathrm{t}) \quad \mathrm{t}=0,1,2, \ldots, \mathrm{T}-1,
$$

where $v_{2}^{\mathrm{T}}$ are used in order to adjust scale. It is easy to see $r(t) \geqq 0 t=0,2, \ldots, T-1$ because $x(t) t=0,1,2, \ldots, T$ represent the optimal paths and satisfy the condition of the problem. Then we reform the above equation as follows.

$$
(I-A+B) z(t)-v_{2} B z(t+1)=r(t) \quad t=0,1,2, \ldots, T-1,
$$

where $z(t)=v_{2}{ }^{-t} x(t) t=0,1,2, \ldots, T$. Then $r(t)$, multiplied by Neumann price $p$, express the value loss. The total value loss is measured by $\sum_{\mathrm{t}=0}^{\mathrm{T}-1} \operatorname{pr}(\mathrm{t})$, which is clearly equal to $\sum_{t=0}^{T-1} \hat{p}_{2} r_{2}(t)$, because the Neumann prices of the 1 st-economy products are equal to 0 . By the way, this value loss of 2 nd-economy is represented as follows.

$$
\begin{aligned}
\sum_{\mathrm{t}=0}^{\mathrm{T}-1} \hat{\mathrm{p}}_{2} \mathrm{r}_{2}(\mathrm{t}) & =\sum_{\mathrm{t}=0}^{\mathrm{T}-1} \hat{\mathrm{p}}_{2}\left[\left(\mathrm{I}_{2}-\mathrm{A}_{22}+\mathrm{B}_{22}\right) \mathrm{z}_{2}(\mathrm{t})-\mathrm{v}_{2} \mathrm{~B}_{22} \mathrm{z}_{2}(\mathrm{t}+1)\right] \\
& =\sum_{\mathrm{t}=0}^{\mathrm{T}-1} \hat{\mathrm{p}}_{2}\left(\mathrm{I}_{2}-\mathrm{A}_{22}+\mathrm{B}_{22}\right) \mathrm{z}_{2}(\mathrm{t})-\sum_{\mathrm{t}=1}^{\mathrm{T}} \mathrm{v}_{2} \hat{\mathrm{p}}_{22} \mathrm{~B}_{22} \mathrm{z}_{2}(\mathrm{t})
\end{aligned}
$$




$$
\begin{aligned}
= & \hat{\mathrm{p}}_{2}\left(\mathrm{I}_{2}-\mathrm{A}_{22}+\mathrm{B}_{22}\right) \mathrm{z}_{2}(0)-\hat{\mathrm{p}}_{2}\left(\mathrm{I}_{2}-\mathrm{A}_{22}+\mathrm{B}_{22}\right) \mathrm{z}_{2}(\mathrm{~T}) \\
& +\sum_{\mathrm{t}=1}^{\mathrm{T}-1} \hat{\mathrm{p}}_{2}\left(\mathrm{I}_{2}-\mathrm{A}_{22}-\mathrm{g}_{2} \mathrm{~B}_{22}\right) \mathrm{z}_{2}(\mathrm{t}) \\
= & \hat{\mathrm{p}}_{2}\left(\mathrm{I}_{2}-\mathrm{A}_{22}+\mathrm{B}_{22}\right) \mathrm{z}_{2}(0)-\hat{\mathrm{p}}_{2}\left(\mathrm{I}_{2}-\mathrm{A}_{22}+\mathrm{B}_{22}\right) \mathrm{z}_{2}(\mathrm{~T}),
\end{aligned}
$$

where we use equation (4) and (7) taking into account the decomposability. By the way, $\left(I_{2}-A_{22}+B_{22}\right) z_{2}(T) \geqq q^{*} s_{2}$ and $q^{*} \geqq \hat{q}$ allow us to generate following inequality.

$$
\sum_{\mathrm{t}=0}^{\mathrm{T}-1} \hat{\mathrm{p}}_{2} \mathrm{r}_{2}(\mathrm{t}) \leqq \hat{\mathrm{p}}_{2}\left(\mathrm{I}_{2}-\mathrm{A}_{22}+\mathrm{B}_{22}\right) \mathrm{z}_{2}(0)-\hat{\mathrm{p}}_{2} \hat{\mathrm{q}} \mathrm{s}_{2} \text {. }
$$

Thus we see that the value loss has a ceiling expressed by the right-hand side of above inequality. And it is especially important that the ceiling is independent of the planning term $T$. Therefore if the length of planning term is sufficiently long, the path of 2nd-economy is near by one of own Leontief trajectory for the most of periods. Then we can prove that the Leotief trajectory converging is the special one which is a halfline spanned by Neumann configuration in positive orthant of the products space of the 2nd-economy. This proof can be given by the methods of Tsukui and Murakami (1979) with a slight modification ${ }^{2}$.

\section{The paths of 1st-economy and the efficiency of growth planning}

The above are discussions about the normative properties of 2nd-economy and its turnpike stability. On the other hand, how does the path of 1st-economy behave while the 2nd-economy is converging to the turnpike ? It may be thought that the 1steconomy converge to the halfine spanned by $\tilde{\mathrm{x}}$ on the positive orthant of own products space. Since this paths are, as mentioned earlier, the supporting paths of 2 nd-economy on the turnpike, it may be possible, but not necessarily. Actually, we can provide many condition which result in other possibilities of optimal paths of 1st-economy. This implies that the 1st-economy does not generally show turnpike property in problem A. It shall be caused by the excess capital stocks of 1st-economy ; its capital stocks are more than enough to support the growth of 2 nd-economy, which is a sector

2) It is easily seen that this Leontief trajectory is nothing but the turnpike. Because to couverge to that paths means that the optimal paths can be approximated to one of difference equation. Since we can prove that the optimal paths remain in the positive orthant of products space, the growth factors, which have greater absolute value than that of Neumann growth factor (eigenvector involves negative factors necessarily), cannot be dominate. Therefore the optimal paths converge to the turnpike. 
limited to attain a maximal capital growth because of the low capability of growth. In this case, we cannot decide the unique growth path of the 1st-economy, because the problem has no criterion when the surplus capital stocks should be discarded on the way of optimal paths. Moreover, we can construct another type of models to discuss such problem. First, we consider the following.

(PROBLEM B)

$\max . \mathrm{q}_{\mathrm{b}}$

s.t.

$$
\begin{aligned}
& \left(I_{2}-A_{22}+B_{22}\right) x_{2}(t)-B_{22} x_{2}(t+1) \geqq 0 \quad t=0,1,2, \ldots, T-1 \\
& \left(I_{2}-A_{22}+B_{22}\right) x_{2}(T)-q_{b} V_{2}^{\top} s_{2} \geqq 0 \\
& x_{2}(t) \geqq 0 \quad t=0,1,2, \ldots, T
\end{aligned}
$$

The main difference between this problem and problem $A$ is that this presume the supply from 1st-economy never restrict the growth of 2nd-economy, in other words, products which are necessary for growth of the 2nd-economy are completely supplied. Then the quantities to be supplied from 1st-economy are defined as follows,

$$
\begin{aligned}
& \mathrm{w}(\mathrm{t})=\left(\mathrm{A}_{12}-\mathrm{B}_{12}\right) \mathrm{x}_{2}(\mathrm{t})+\mathrm{B}_{12} \mathrm{x}_{2}(\mathrm{t}+1) \mathrm{t}=0,1,2, \ldots, \mathrm{T}-1 \\
& \mathrm{w}(\mathrm{t})=\left(\mathrm{A}_{12}-\mathrm{B}_{12}\right) \mathrm{x}_{2}(\mathrm{~T}),
\end{aligned}
$$

where $x_{2}(t) t=1,2, \ldots, T$ are the solution of problem $B$. Then we construct the dynamic Leontief inverse of 1st-economy as follows.

$$
\begin{aligned}
& \left(I_{1}-A_{11}+B_{11}\right) x_{1}{ }^{*}(t)-B_{11} x_{1}{ }^{*}(t+1)=w(t) t=0,1,2, \ldots, T-1 \\
& \left(I_{1}-A_{11}+B_{11}\right) x_{1}{ }^{*}(T)-\mathrm{q}_{b} v_{2}{ }^{T} S_{1}=w(T),
\end{aligned}
$$

where $q_{b}$ is the optimal solution of problem $B$. This series $x_{1}^{*}(t) t=0,1,2, \ldots, T$ are the paths which support the optimal growth of 2nd-economy and attain its own capital stock scaled by $q_{b}$. This dynamic Leontief inverse would remain in positive orthant because of the complete instability of Leontief trajectories in actual data, as is shown in Tsukui and Murakami (1979). In later numerical example, we will examine whether this proposition holds or not.

The arbitrariness of 1 st-economy is occured when the following inequality is satisfied.

$$
\left(I_{1}-A_{11}+B_{11}\right) x_{1}(0)-\left(I_{1}-A_{11}+B_{11}\right) x_{1}^{*}(0)>0,
$$

where $x_{1}(0)$ is the initial vector given in the problem. Thus the residuals of this left -hand side are excess initial capital stocks in attaining maximal objective value. Therefore the various paths are possible as optimal growth path of 1st-economy by using those excess capitals arbitrarily. 
By the way, is the reverse situation, in which the lst-economy become a bottlenech and the 2nd-economy has a surplus, possible? This situation, however, will not appear clearly, because in such case, the 1st-economy always can reach to the higher production level by using products which are obtained by reducing the growth capability of 2nd-economy. Furthermore if the planning term is long enough, 1st-economy never becomes a growth limiting sector, because of its high capacity to grow. We can say that the situation above discussed show inefficiency of the planning. Though this depends upon the objective function conclusively, ours is not so special one and commonly used when we pay much attention to the proportion of scale of industries. Moreover, when there exists such excess capital stocks, we would be able to reconsider the structure of basic model. For example, by changing trade structure of the model, we can increase the export of the products of 1st-economy, and the import of the products of 2nd-economy, and achieve the higher level of the final scale of economic activity.

We can also construct an additional optimal growth problem by using its surplus, estimated as the left-hand side of (9).

(PROBLEM C)

$\max . \mathrm{q}_{\mathrm{c}}$

s.t.

$$
\begin{aligned}
& R-B_{11} x_{1}(1) \geqq 0 \\
& \left(I_{1}-A_{11}+B_{11}\right) x_{1}(t)-B_{11} x_{1}(t+1) \geqq 0 \quad t=1,2, \ldots, T-1 \\
& \left(I_{1}-A_{11}+B_{11}\right) x_{1}(T)-q_{c} v_{2}{ }^{T} \widetilde{S}_{1} \geqq 0 \\
& x_{1}(t) \geqq 0 \quad t=1,2, \ldots, T,
\end{aligned}
$$

where $R$ represents the left-hand side of (9) and $\widetilde{s}_{1}$ may be different from $s_{1}$ used previously. We can regard $\mathrm{q}_{c}$ as the other kind of estimator of inefficiency. As a result, when the planning problem involves the situation of (9), we may consider the planning by two stages. First we solve the problem $\mathrm{B}$, then do the problem $\mathrm{C}$, and the objective path will be combination of two solutions.

The above discussions are conclusively depending upon the situation in which (9) is satisfied. This criterion of inefficiency may, however, be too strong. Therefore, we shall define a weaker condition of planning inefficiency;

Let the solution of problem A be $\mathrm{q}^{*}$, and the products of 1st-economy to support the growth of 2 nd-economy be $w(t) t=0,1,2, \ldots, T$ as defined by (8). Then we consider the optimal growth problem, 
(PROBLEM D)

$$
\begin{aligned}
& \max . q_{d} \\
& \text { s.t. } \\
& \left(I_{1}-A_{11}+B_{11}\right) x_{1}-B_{11} x_{1}(t+1) \geqq w(t) \quad t=0,1,2, \ldots, T-1 \\
& \left(\mathrm{I}_{1}-\mathrm{A}_{11}+\mathrm{B}_{1 \mathrm{I}}\right) \mathrm{x}_{1}(\mathrm{~T})-\mathrm{q}_{\mathrm{d}} \mathrm{v}_{2}{ }^{\mathrm{T}} \mathrm{s}_{1} \geqq \mathrm{w}(\mathrm{T}) \\
& \mathrm{x}_{1}(\mathrm{t}) \geqq 0 \quad \mathrm{t}=0,1,2, \ldots, \mathrm{T},
\end{aligned}
$$

where $x_{1}(0)$ is same initial vector as given in problem $A$. If $q_{d}>q^{*}$ is satisfied for the solution $\mathrm{q}_{\mathrm{d}}$ of problem $\mathrm{D}$, we say that the original planning is inefficient.

We should notice here the difference between this method and the one expressed by problem B and inequality (9). The important point is that even if the inequality (9) does not hold, $q_{d}>q^{*}$ may, because the former method depend upon the use of the dynamic Leontief inverse. If we use the programming method to minimize the initial stocks to realize same final demand as in the dynamic Leontief inverse, then the condition (9) is equivalent to the condition $\mathrm{q}_{d}>\mathrm{q}^{*}$.

Further, we should pose a additional remark for the discussion in a numerical example section. If the optimal $\mathrm{q}$ in original problem, $\mathrm{q}^{*}$, is smaller than that of the planning which is constructed only for 2nd-economy, $\mathrm{q}_{\mathrm{b}}$, such planning is efficient, because in such situations, the 1st-economy always restricts the growth of the 2ndeconomy compared with the case ignoring any support of the 1st-economy.

\section{The numerical examples of Japanese economy}

Of the above theoretical discussions, we shall here examine its reality using Japanese data, publicized by the Economic Planning Agency (1971). These are well prepared containing input coefficient matrixes, capital coefficient matrixes, value added vector . First we aggregate 56 industies in the above data into 23 industries. Then to make them decomposable, as above discussed, we arrange the industries as follows.

(1st-economy)

1 , Iron and steel

2, Metal products

3, Machinery

4, Electric machinery

5, Transportation equipment

6. Construction

7, Electricity and water (2nd-economy)

12, Agriculture

13, Mining

14, Food products

15, Textiles and clothes

16, Lumber and furniture

17. Pulp and paper

18. Leather and rubber 

8, Commerce
19. Chemical
9. Finance and insurance
20, Oil and coal
10, Transport
21, Ceramics
11, Services
22, Precision instruments
23, Other manufacturing

We can employ two methods to make A and B matrixes be completely decomposable, in keeping the technological input-output situation close to the original economy as well as possible.

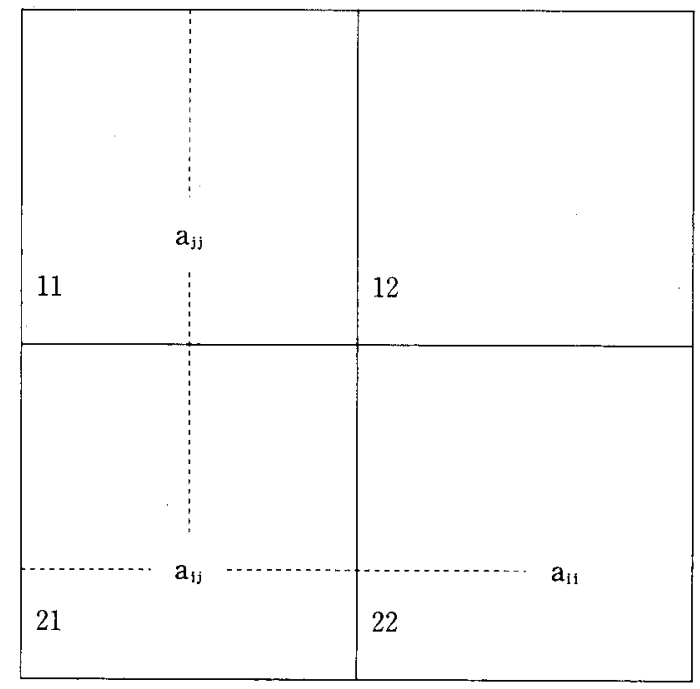

In the above figure, 1 imply the set of numbers of industries belonging 1 st-economy and 2 imply the other. In order to make coefficients in area 21 be 0 , one method is to increase $a_{1 i}$ for the compensation of the adjustment of letting $a_{1 j}$ 's be 0 under certain criterion. The other is to increase $a_{j j}$. Tsukui and Murakami (1979) employed the first method and its criterion is the following. Let the production level of ith products be $X_{i}$ and jth products be $X_{j}$ in the base year. Then the ith products used for the production of $\mathrm{X}_{j}$ is $\mathrm{a}_{\mathrm{ij}} \mathrm{X}_{j}$. We suppose that this amount of products are imported from the foreign countries and the same amount of products of ith industry are exported to attain the balance of trade. Thus the new coefficient $\mathrm{a}_{\mathrm{i1}}{ }^{*}$ are decided as follows.

$$
a_{11}^{*}=a_{11}+a_{1 j} X_{j} / X_{1} \text {. }
$$

This treatment may, however, cause some difficulties because the new coefficient depend upon the ratio of productions, $\mathrm{X}_{\mathrm{j}} / \mathrm{X}_{\mathrm{i}}$, as it is clear from the above equation. That is, the approximation may become insufficient for a long-term problem, because 
the optimal paths or the actual paths do not necessarily keep this configuration $X_{j} / X_{i}$. The second method is to assume that an additional amount of products of jth industry are exported and $a_{i j} X_{j}$ 's are imported by paying this export gain. Thus, we can let $a_{i j}$ 's be 0 and the new coefficient $a_{j j}{ }^{*}$ is defined as follows.

$$
a_{j j}{ }^{*}=a_{j j}+a_{i j} X_{j} / X_{j}=a_{j j}+a_{i j} \text {. }
$$

Then $\mathrm{a}_{1 \mathrm{j}}{ }^{*}$ does not depend on any levels of production. Nevertheless, this method has a fault that it depend upon prices, because the above calculation is performed under the valuation of products at the base year prices. Consequently, we can conclude that the two methods have both merits and demerits.

Furthermore, we must consider the fact that, if we employ the first method, growth capability of 2nd-economy decreases and, if we employ the second method, that of 1st-economy decreases. In this paper we are studying the situation in which the Neumann growth rate of 2nd-economy is lower than that of 1st-economy. Therefore, it may not be able to employ the second method exclusively. On the other hand, it may not be appropriate to employ the first method exclusively, because the growth rate of 1st-economy become unusually high in some cases. Therefore we tentatively tried to share $a_{i j} X_{j}$ to $a_{1 i}$ and $a_{j j}$ with the ratio $4: 1$. Then, the Neumann solutions of each economy are given as follows.

\begin{tabular}{|c|c|}
\hline 1st-economy & 2nd-economy \\
\hline $\mathrm{g}_{1}=0.31913$ & $\mathrm{~g}_{2}=0.28355$ \\
\hline$\hat{\mathrm{x}}_{1}=1, \quad 16.64$ & $\widehat{\mathbf{x}}_{2}=12, \quad 13.67$ \\
\hline $2, \quad 4.13$ & 13 \\
\hline $3, \quad 10.76$ & 6.38 \\
\hline $4, \quad 8.20$ & 6.52 \\
\hline $5, \quad 8.22$ & $16, \quad 21.82$ \\
\hline $6, \quad 20.58$ & 5.21 \\
\hline $7, \quad 2.06$ & $18, \quad 1.68$ \\
\hline $8, \quad 10.66$ & $19, \quad 11.16$ \\
\hline $9, \quad 4.74$ & 6.19 \\
\hline $10, \quad 5.95$ & 21, \\
\hline $11, \quad 8.06$ & $22, \quad 11.28$ \\
\hline & $23, \quad 8.87$ \\
\hline
\end{tabular}

where the output configuration is normalized to let the sum of component be 100 .

Before solving the problem $A$, we replace $\mathrm{qv}_{2}{ }^{\mathrm{T}} \mathrm{S}$ with qs, because $\mathrm{v}_{2}{ }^{\mathrm{T}}$ does not play any rolls in this stage. Moreover, we define as $\mathrm{s}=\mathrm{Bx}_{1965}$. Since we set the starting period in 1965 , this means that our objective is to increase the amount of final stock 
keeping the proportion of initial stock. The planning period is assumed as $\mathrm{T}=10$.

The solution of problem $A$ is $q=1.768$. This shows that we can attain the final capital stocks which are 1.768 times as large as the initial one. The average growth rate during the planning period is $5.864 \%$. And in the optimal solution we can recognize the corroboration of our theory to some extent. Figure-1, 2 show the optimal paths. In these figures, we can discern rather clear differences between paths of two economies. Many of the paths of 1st-economy are that of S shape, i.e., first the level of production falls into the bottom, then changes the direction with a sharp upturn and reaches to maximal point before the final period. Moreover we can say that many of this behavior appear in the industries of investment products. And the characteristic, which the paths of 1st-economy have commonly, is the sharpness of upturn. On the other hand, the paths of 2nd-economy represent a geometric expansion curve of upturn after the sharp downwards swing like that of 1st-economy and very few reach maximal point before the final period. Furthermore, we shall investigate the optimal paths from the view point of the proportion showed in table-1. In the paths of 1steconomy, we can see that the period for the configuration to become stable is 4 th or 5th period. And after that, it can be thought, the paths converge to the turnpike of itself. Thus we see that the downwards swing in first period is necessary to approach the turnpike. Nevertheless, we should notice the fact that the growth rate does not approach to the Neumann growth rate, because the upwards path is not geometric. Owing to the above observations, we can conclude that 1st-economy has the surplus of activities to some extent in the later periods.

On the other hand, the configuration of 2nd-economy shows us that many of the paths converge to the turnpike in 3rd period. We must, however, pay attention to the fact that there exists industries, e.g. no. 14 and no. 16, which must change the directions seriously. Since the objective configuration is same as that in initial period, these industries should change the directions to the objective configuration again and gradually diverge from the turnpike. Nevertheless, we can conclude that the paths of 2nd-economy converge to the turnpike with Neumann growth rate.

Now, we evaluate the efficiency of planning, using the method explained in the previous section. First, we shall solve the problem which ignore $A_{12}, B_{12}$, that is, correspond to problem $\mathrm{B}$, previously mentioned. Table-2 shows the configuration on optimal path. We see that the path already converge to the turnpike in 2nd period. 
Also $\mathrm{q}_{\mathrm{b}}$ is achieved 3.631. Moreover, the Leontief dynamic inverse path of the independent sub-economy is easily obtained and the result corresponding to (9) is the following.

$\begin{array}{lccc}\text { IND. } & \text { INT. STOCK } & \text { SUP. STOCK } & \text { IS/SS } \\ \text { No. } 1 & 520.85 & 1880.57 & 0.277 \\ \text { No. } 2 & 1471.00 & 2074.20 & 0.709 \\ \text { No. } 3 & 10174.72 & 10708.88 & 0.950 \\ \text { No. } 4 & 6276.28 & 5894.48 & 1.065 \\ \text { No. } 5 & 6997.75 & 6658.00 & 1.051 \\ \text { No. } 6 & 33305.88 & 29864.72 & 1.115 \\ \text { No. } 7 & 648.76 & 739.74 & 0.877 \\ \text { No. } 8 & 3533.94 & 5716.07 & 0.618 \\ \text { No. } 9 & 1238.19 & 1676.59 & 0.739 \\ \text { No.10 } & 2658.57 & 2288.68 & 1.162 \\ \text { No.11 } & 5603.46 & 2757.73 & 2.032\end{array}$

The first column represents the vector of initial stocks, second column represent the initial stocks vector which supports the optimal growth by above method, third column represent these ratios. In many of capital stocks, the shortage occurred actually. But the fact that there exists the shortage of some stocks does not directly show the efficiency of planning, because above discussion decisively depends upon use of the dynamic Leontief inverse as previously mentioned. Nevertheless, we can already see that the original planning is efficient, because $q^{*}<q_{b}$ is fulfilled. Since, if planning is efficient, the dependent sub-economy is supplied products from the independent sub-economy as sufficient as it needs, $q^{*}=q_{b}$ must be fulfilled. 


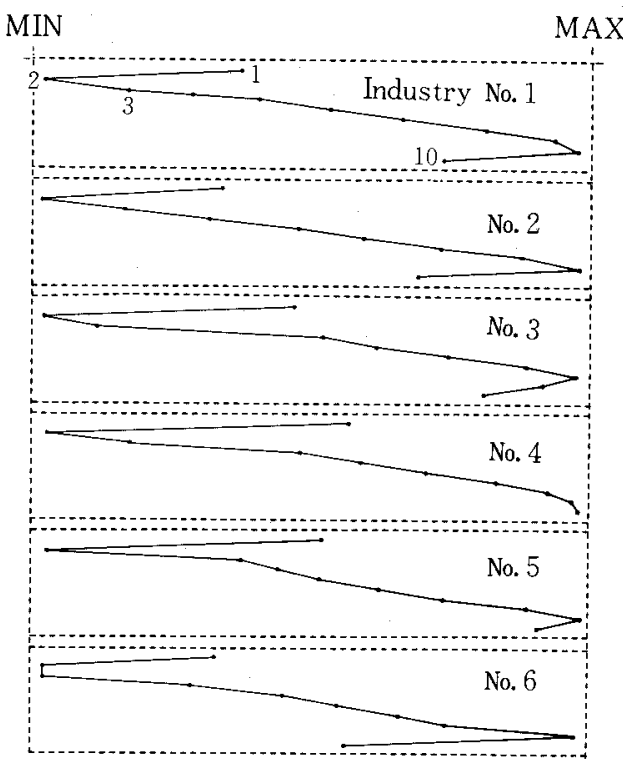

Figure-1(1)

AX

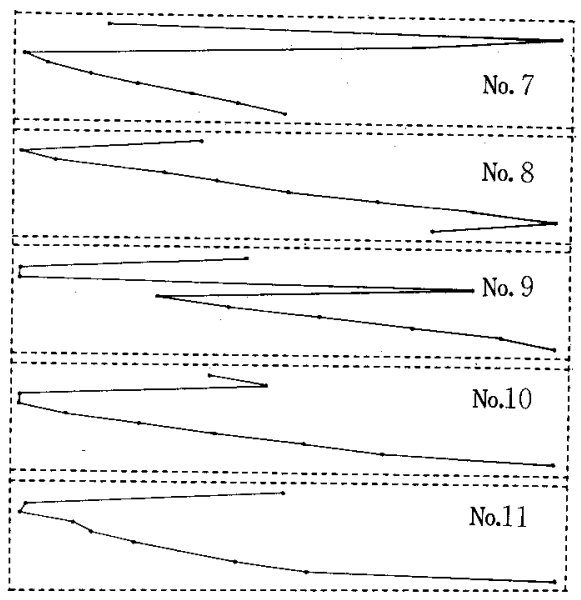

Figure-1(2)

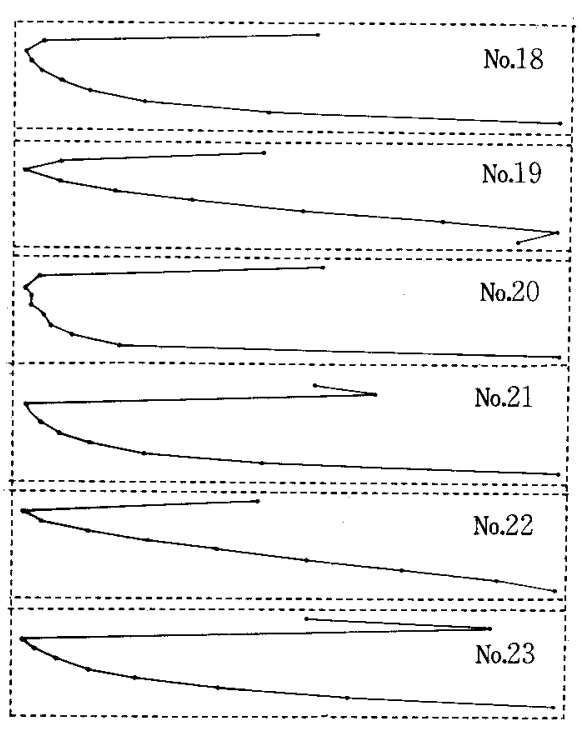

Figiure-2(2)
No.12

No.13

№.14

№.15

No.16

No.17
Figure-2(1)

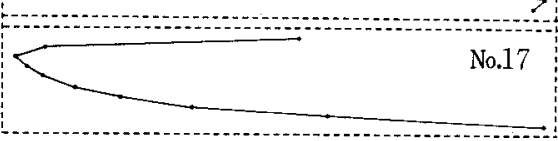


Table-1 (1)

\begin{tabular}{c|rrrllllllll}
\hline No. & \multicolumn{1}{c}{1} & 2 & \multicolumn{1}{c}{3} & \multicolumn{1}{c}{4} & \multicolumn{1}{c}{5} & \multicolumn{1}{c}{6} & \multicolumn{1}{c}{7} & \multicolumn{1}{c}{8} & \multicolumn{1}{c}{9} & \multicolumn{1}{c}{10} & 11 \\
\hline 1 & 12.0 & 3.1 & 7.5 & 7.3 & 8.0 & 13.5 & 3.1 & 10.6 & 6.6 & 9.3 & 18.9 \\
2 & 9.0 & 2.4 & 0. & 0. & 0. & 0. & 25.1 & 12.2 & 8.2 & 28.2 & 15.0 \\
3 & 15.7 & 4.2 & 3.5 & 4.6 & 12.6 & 0. & 16.6 & 12.9 & 6.6 & 11.9 & 11.4 \\
4 & 15.3 & 3.5 & 9.9 & 7.4 & 8.0 & 14.2 & 2.3 & 11.2 & 12.4 & 6.3 & 9.5 \\
5 & 16.2 & 4.0 & 10.1 & 7.7 & 8.0 & 19.5 & 2.3 & 11.4 & 5.2 & 6.4 & 9.1 \\
6 & 16.1 & 4.0 & 10.1 & 7.7 & 8.0 & 19.4 & 2.3 & 11.5 & 5.3 & 6.4 & 9.2 \\
7 & 15.8 & 4.0 & 9.9 & 7.5 & 7.9 & 19.4 & 2.4 & 11.6 & 5.4 & 6.5 & 9.5 \\
8 & 15.5 & 4.0 & 9.5 & 7.3 & 8.3 & 19.0 & 2.5 & 11.9 & 5.6 & 6.7 & 9.8 \\
9 & 14.2 & 3.9 & 7.8 & 6.6 & 8.1 & 22.0 & 2.5 & 12.0 & 5.7 & 6.7 & 10.5 \\
10 & 12.0 & 3.1 & 7.5 & 7.3 & 8.0 & 13.5 & 3.1 & 10.6 & 6.6 & 9.3 & 18.9 \\
\hline Turnpike & 16.6 & 4.1 & 10.8 & 8.2 & 8.2 & 20.6 & 2.1 & 10.7 & 4.7 & 6.0 & 8.1
\end{tabular}

Table-1 (2)

\begin{tabular}{c|rrrrrrrrrrrr}
\hline $\mathrm{T}^{\text {No. }}$ & \multicolumn{1}{c|}{12} & \multicolumn{1}{c}{13} & \multicolumn{1}{c}{14} & \multicolumn{1}{c}{15} & \multicolumn{1}{c}{16} & \multicolumn{1}{c}{17} & 18 & 19 & 20 & 21 & 22 & 23 \\
\hline 1 & 18.8 & 1.9 & 22.5 & 11.2 & 5.6 & 5.0 & 2.1 & 11.4 & 5.2 & 3.7 & 2.1 & 10.5 \\
2 & 6.6 & 1.9 & 4.7 & 34.6 & 5.8 & 20.6 & 0.9 & 12.9 & 3.7 & 1.4 & 1.7 & 5.3 \\
3 & 13.5 & 4.4 & 6.4 & 6.8 & 20.9 & 5.3 & 1.7 & 11.6 & 6.6 & 3.5 & 9.9 & 9.4 \\
4 & 13.4 & 4.7 & 6.4 & 6.9 & 20.2 & 5.4 & 1.7 & 11.8 & 6.8 & 3.6 & 9.4 & 9.7 \\
5 & 13.3 & 4.9 & 6.4 & 7.1 & 19.2 & 5.5 & 1.7 & 12.1 & 7.0 & 3.7 & 8.9 & 10.1 \\
6 & 13.3 & 5.2 & 6.5 & 7.4 & 17.7 & 5.7 & 1.8 & 12.6 & 7.3 & 3.9 & 8.0 & 10.6 \\
7 & 13.5 & 5.2 & 6.6 & 7.9 & 15.7 & 5.9 & 1.8 & 13.3 & 7.6 & 4.1 & 7.0 & 11.3 \\
8 & 14.6 & 4.9 & 6.9 & 8.7 & 13.0 & 6.1 & 1.9 & 14.3 & 7.8 & 4.4 & 5.6 & 11.9 \\
9 & 17.2 & 3.8 & 8.1 & 10.0 & 9.8 & 6.1 & 2.0 & 14.8 & 7.4 & 4.4 & 4.0 & 12.3 \\
10 & 18.8 & 1.9 & 22.5 & 11.2 & 5.6 & 5.0 & 2.1 & 11.4 & 5.2 & 3.7 & 2.1 & 10.5 \\
\hline Turnpike & 13.7 & 3.8 & 6.4 & 6.5 & 21.8 & 5.2 & 1.7 & 11.2 & 6.2 & 3.4 & 11.3 & 8.8 \\
& & & & & & & & & & & &
\end{tabular}

Table-2

\begin{tabular}{c|rrrrrrrrrrrr}
\hline $\mathrm{T}^{\text {No. }}$ & 12 & 13 & \multicolumn{1}{c}{14} & \multicolumn{1}{c}{15} & \multicolumn{1}{c}{16} & \multicolumn{1}{c}{17} & 18 & 19 & 20 & 21 & 22 & 23 \\
\hline 1 & 18.8 & 1.9 & 22.5 & 11.2 & 5.6 & 5.0 & 2.1 & 11.4 & 5.2 & 3.7 & 2.1 & 10.5 \\
2 & 13.6 & 4.3 & 6.4 & 6.7 & 21.4 & 5.3 & 1.7 & 11.4 & 6.5 & 3.5 & 10.2 & 9.2 \\
3 & 13.5 & 4.4 & 6.4 & 6.8 & 20.9 & 5.3 & 1.7 & 11.6 & 6.6 & 3.5 & 9.9 & 9.4 \\
4 & 13.4 & 4.7 & 6.4 & 6.9 & 20.2 & 5.4 & 1.7 & 11.8 & 6.8 & 3.6 & 9.4 & 9.7 \\
5 & 13.3 & 4.9 & 6.4 & 7.1 & 19.2 & 5.5 & 1.7 & 12.1 & 7.0 & 3.7 & 8.9 & 10.1 \\
6 & 13.3 & 5.2 & 6.5 & 7.4 & 17.7 & 5.7 & 1.8 & 12.6 & 7.3 & 3.9 & 8.0 & 10.6 \\
7 & 13.5 & 5.2 & 6.6 & 7.9 & 15.7 & 5.9 & 1.8 & 13.3 & 7.6 & 4.1 & 7.0 & 11.3 \\
8 & 14.6 & 4.9 & 6.9 & 8.7 & 13.0 & 6.1 & 1.9 & 14.3 & 7.8 & 4.4 & 5.6 & 11.9 \\
9 & 17.2 & 3.8 & 8.1 & 10.0 & 9.8 & 6.1 & 2.0 & 14.8 & 7.4 & 4.4 & 4.0 & 12.3 \\
10 & 18.8 & 1.9 & 22.5 & 11.2 & 5.6 & 5.0 & 2.1 & 11.4 & 5.2 & 3.7 & 2.1 & 10.5
\end{tabular}




\section{References}

(1) Bromek, T., (1974), "Comsumption-Investment Frontier in von Neumann Models" in Los, J. and M. W. Los, eds., Mathematical Models in Economic, North-Holland Pub. Co..

(2) Economic Planning Agency, (Tsukui, J., other 1971), "Estimation of s. 40, 56-sec. Capital Coefficient Matrix and the Calculation of Equilibrium Growth Path (In Japanese)," Keizaibunseki No, 35.

(3) Leontief, W., (1972), "The Dynamic Inverse," A. P. Carter and A. Brody, eds., Contributions to Input-Output Analysis published in honor of Wassily Leontief North -Holland.

(4) McKenzie, L. W., (1967), "Maximal Paths in the von Neumann Model," in Bacharach, M. O. L. and E. Malinvaud, eds., Activity Analysis in the Theory of Growth and Planning, London.

(5) McKenzie, L. W., (1968), "Accumulation Programs of Maximal Utility and the von Neumann Facet," J. N. Wolfe, eds., Value, Capital and Growth, Edinburg University Press.

(6) Morishima, M., (1970), Theory of Economic Growth, Oxford University Press.

(7) Morishima, M., (1971), "Consumption-investment Frontier, Wage-profit Frontier, and the von Neumann Growth Equilibrium," Zeitschrift für Nationalöconomie, Suppl. 1.

(8) Morishima, M., (1976), "Marx from a von Neumann Viewpoint," M. Brown, K. Sato and P. Zarembka, eds., Essays in Modern Capital Theory, North-Holland.

(9) Simpson, D. and J. Tsukui, (1965), "The Fundamental Structure of Input-Output Table, An International Comparison," The Review of Economics and Statistics, Vol. XLVII, No. 4.

(10) Tsukui, J., (1967), "The Consumtion and The Output Turnpike Theorem in a von Neumann Type of Model-A Finite Term Problem," The Review of Economic Studies, Vol. 34

(11) Tsukui, J. and Y. Murakami, (1979), Turnpike Optimality in Input-Output SystemsTheory and Application for Planning, North-Holland.

(12) Tsukui, J. and J. Móczár, (1984), "Optimal Growth Paths and Multiple Turnpikes in a decomposable Economy," discussion paper in Institute of Social and Economic Research, Osaka University. 